\title{
COMMENTARY
}

\section{Monitoring treatment response in abdominal sepsis with procalcitonin - if only!}

\author{
Christian Eckmann ${ }^{1 *}$ and Miguel Sanchez-Garcia ${ }^{2}$ \\ See related research by Jung et al., http://ccforum.com/content/17/5/R255
}

\begin{abstract}
The ideal management of infection includes not only the early identification and start of effective therapy but also the correct categorization of non-infected patients in order to avoid unnecessary use of antimicrobials. The availability of a specific and sensitive test for the presence of infection is of paramount importance to improve the prudent use of antimicrobial therapy. Procalcitonin (PCT) has been evaluated over recent years as to whether it can be used to detect the presence of different types of infection, allows reduced duration of antibiotic therapy, or predicts treatment failure or adverse outcome. In the previous issue of Critical Care, Jung and colleagues report about the monitoring of treatment response in abdominal sepsis by repetitive determination of $\mathrm{PCT}$.
\end{abstract}

Robust data assessing the value of procalcitonin (PCT) for monitoring treatment response in abdominal sepsis are rare, so the study of Jung and colleagues published in the previous issue of Critical Care is most welcome [1]. They concluded that a decrease of PCT to $0.5 \mathrm{ng} / \mathrm{ml}$ lacked sensitivity to predict treatment response and a decrease of at least $80 \%$ from its peak failed to accurately predict treatment response. The value of the study is limited by the small number of patients included, the single-center approach and its observational character. Nevertheless, it is to date among the best available evidence we have for these critically ill patients.

International databases show that one in four cases of severe sepsis or septic shock is caused by intraabdominal infection. It is the second most common

\footnotetext{
* Correspondence: christian.eckmann@klinikum-peine.de

'Department of General, Visceral and Thoracic Surgery, Klinikum Peine, Academic Hospital of Medical University Hannover, Virchowstrasse 8h, D-31226 Peine, Germany

Full list of author information is available at the end of the article
}

cause of septic shock after pulmonary causes [2,3]. Abdominal sepsis is not just a single disease, but comprises a group of different entities. Almost $90 \%$ of all intraabdominal infections are so-called secondary peritonitis and require a primarily surgical approach $(87 \%$ of patients had surgical intervention in the study of Jung and colleagues). Secondary peritonitis consists of community acquired and postoperative nosocomial forms, the latter one following a previous surgical intervention (anastomotic insufficiency following anterior rectum resection). Tertiary nosocomial peritonitis is a persistent intraabdominal infection without a surgically treatable focus [4], but this point is difficult to assess without an uncontributive reoperation proving that the patient indeed has a tertiary peritonitis. Primary inadequate and inappropriate antibiotic regimens for both forms of nosocomial peritonitis are associated with substantially worse prognostic outcome for patients with intra-abdominal infections and result in substantial increases in health care costs [5].

The difficulties associated with abdominal sepsis are complicated by uncertainty about surgical control of the source of the sepsis. Do we have any reliable parameters that enable us to decide whether to perform a relaparotomy or not (in the Jung and colleagues study about 20 out of 101 patients required a relaparotomy)? Can PCT help us? An analysis of all investigated markers, including PCT, failed to detect specific parameters that can be used under these difficult conditions [6].

Current guidelines recommend administration of broad-spectrum antimicrobials within 1 hour of the diagnosis of severe sepsis or septic shock [7]. This recommendation is based on the evidence that delaying antimicrobial therapy in patients with sepsis- related hypotension is associated with increased mortality [8]. PCT has been evaluated over recent years as to whether it can be used to detect the presence of different types of infection, treatment failure or adverse outcome. The promising initial publications reporting the results of 
using serial serum PCT concentrations to guide duration of antibiotic therapy in patients with communityacquired pneumonia [9] have only partially been confirmed in critically ill patients. A recent randomized multicenter trial enrolling critically ill patients [10] with mainly respiratory tract infection showed that duration of antibiotic therapy can be reduced by a mean of 2.7 days without impact on mortality. But unfortunately, PCT had no influence on the duration of antibiotic therapy in patients with intra-abdominal infections [10]. It seems PCT is much more helpful in pulmonary sepsis than in abdominal sepsis! Smaller randomized studies show that significant PCT-guided reduction of antibiotic exposure can safely be accomplished in patients with severe sepsis and septic shock and in surgical patients with sepsis [11]. More recently, it has been suggested that PCT may be of value as a prognostic marker [12]. Daily measurements of PCT in a general ICU population in a recent large multicenter randomized study [13] were associated with increased use of antibiotics and duration of mechanical ventilation.

This commentary has been written by an abdominal surgeon and an intensivist, representing the two disciplines most frequently involved in the treatment of an important subgroup of critically ill patients. In this 'war' against the high mortality from abdominal sepsis, surgeons and intensivists are brothers in arms. The study of Jung and colleagues indicates that PCT is still a valuable weapon in this war - but far from being the magic bullet.

\section{Abbreviations}

PCT: Procalcitonin.

\section{Competing interests}

The authors declare that they have no competing interests.

\section{Author details}

${ }^{1}$ Department of General, Visceral and Thoracic Surgery, Klinikum Peine, Academic Hospital of Medical University Hannover, Virchowstrasse 8h, D-31226 Peine, Germany. ${ }^{2}$ Servicio de Medicina Intensiva, Hospital Clinico San Carlos, 28040 Madrid, Spain.

Published: 10 Dec 2013

\section{References}

1. Jung B, Molinari N, Nasri M, Hajjej Z, Chanques G, Jean-Pierre H, Panaro F, Jaber S: Procalcitonin biomarker kinetics fails to predict treatment response in perioperative abdominal infection with septic shock. Crit Care 2013, 17:R255

2. Kumar A, Ellis P, Arabi Y, Roberts D, Light B, Parrillo JE, Dodek P, Wood G, Kumar A, Simon D, Peters C, Ahsan M, Chateau D, Cooperative Antimicrobial Therapy of Septic Shock Database Research Group: Initiation of inappropiate antimicrobial therapy results in a fivefold reduction of survival in human septic shock. Chest 2009, 136:1237-1248.

3. Engel C, Brunkhorst FM, Bone HG, Brunkhorst R, Gerlach H, Grond S, Gruendling M, Huhle G, Jaschinski U, John S, Mayer K, Oppert M, Olthoff D, Quintel M, Ragaller M, Rossaint R, Stuber F, Weiler N, Welte T, Bogatsch H, Hartog C, Loeffler M, Reinhart K: Epidemiology of sepsis in Germany: results from a national prospective multicenter study. Intensive Care Med 2007, 33:606-618.
4. Eckmann C, Dryden M, Montravers P, Kozlov R, Sganga G: Antimicrobial treatment of "complicated" intra-abdominal infections and the new IDSA guidelines - a commentary and an alternative European approach. Eur J Med Res 2011, 16:115-126.

5. Barie P: The cost of failure. Surg Infect 2008, 9:313-331.

6. Lamme B, Mahler CW, van Ruler O, Gouma DJ, Reitsma JB, Boermeester MA: Clinical predictors of ongoing infection in secondary peritonitis: systematic review. World J Surg 2006, 30:2170-2181.

7. Dellinger RP, Levy MM, Rhodes A, Annane D, Gerlach H, Opal SM, Sevransky JE, Sprung CL, Douglas IS, Jaeschke R, Osborn TM, Nunnally ME, Townsend SR, Reinhart K, Kleinpell RM, Angus DC, Deutschman CS, Machado FR, Rubenfeld GD, Webb S, Beale RJ, Vincent JL, Moreno R, Surviving Sepsis Campaign Guidelines Committee including The Pediatric Subgroup: Surviving Sepsis Campaign: international guidelines for management of severe sepsis and septic shock, 2012. Intensive Care Med 2013, 39:165-228.

8. Kumar A, Roberts D, Wood KE, Light B, Parrillo JE, Sharma S, Suppes R, Feinstein D, Zanotti S, Taiberg L, Gurka D, Kumar A, Cheang M: Duration of hypotension before initiation of effective antimicrobial therapy is the critical determinant of survival in human septic shock. Crit Care Med 2006, 34:1589-1596.

9. Christ-Crain M, Jaccard-Stolz D, Bingisser R, Gencay MM, Huber PR, Tamm M, Müller B: Effect of procalcitonin-guided treatment on antibiotic use and outcome in lower respiratory tract infections: cluster-randomised, singleblinded intervention trial. Lancet 2004, 363:600-607.

10. Bouadma L, Luyt CE, Tubach F, Cracco C, Alvarez A, Schwebel C, Schortgen F, Lasocki S, Veber B, Dehoux M, Bernard M, Pasquet B, Régnier B, BrunBuisson C, Chastre J, Wolff M, PRORATA trial group: Use of procalcitonin to reduce patients' exposure to antibiotics in intensive care units (PRORATA trial): a multicentre randomised controlled trial. Lancet 2010, 375:463-474.

11. Nobre V, Harbarth S, Graf JD, Rohner P, Pugin J: Use of procalcitonin to shorten antibiotic treatment duration in septic patients: a randomized trial. Am J Respir Crit Care Med 2008, 177:498-505.

12. Schuetz $P$, Maurer $P$, Punjabi V, Desai A, Amin DN, Gluck E: Procalcitonin decrease over 72 hours in US critical care units predicts fatal outcome in sepsis patients. Crit Care 2013, 17:R115.

13. Jensen $J U$, Hein L, Lundgren B, Bestle MH, Mohr TT, Andersen MH Thornberg KJ, Løken J, Steensen M, Fox Z, Tousi H, Søe-Jensen P, Lauritsen $A \varnothing$, Strange D, Petersen PL, Reiter N, Hestad S, Thormar K, Fjeldborg P, Larsen KM, Drenck NE, Ostergaard C, Kjær J, Grarup J, Lundgren JD, Procalcitonin And Survival Study (PASS) Group: Procalcitonin-guided interventions against infections to increase early appropriate antibiotics and improve survival in the intensive care unit: a randomized trial. Crit Care Med 2011, 39:2048-2058.

$10.1186 / \mathrm{cc} 13154$

Cite this article as: Eckmann and Sanchez-Garcia: Monitoring treatment response in abdominal sepsis with procalcitonin - if only! Critical Care 2013, 17:1017 